\title{
Midterm outcomes of early versus late surgery for infective endocarditis with neurologic complications: a meta-analysis
}

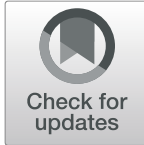

\author{
Yujiro Yokoyama ${ }^{1}$ and Taichiro Goto ${ }^{2^{*}}$ (D)
}

\begin{abstract}
Background: Cerebral infarction (Cl) remains one of the most common and fatal complications of infective endocarditis (IE), and the timing of surgery for IE with neurologic complications is controversial. As outcomes beyond the perioperative period have not been assessed with a meta-analysis previously, we conducted a metaanalysis comparing mid- to long-term outcomes of early and late surgery in patients with IE and neurologic complications.
\end{abstract}

Methods: All studies that investigated early and late surgery in patients with IE and neurologic complications were identified. The primary and secondary endpoints were all-cause mortality and recurrence, respectively. Hazard ratios (HRs) for all-cause mortality and recurrence were extracted from each study.

Results: Our search identified five eligible studies, which were all observational studies consisting of a total of 624 patients with IE and neurologic complications. Pooled analyses demonstrated that all-cause mortality was similar between the early and late surgery groups (HR $[95 \%$ confidence interval $[C I]]=0.90[0.49-1.64] ; P=0.10 ; I^{2}=49 \%$ ). Similarly, the recurrence rates were similar between both groups (HR $[95 \% \mathrm{Cl}]=1.86[0.76-4.52] ; P=0.43 ; I^{2}=0 \%$ ).

Conclusions: Our meta-analysis showed similar mortality and recurrent rates between the early and late surgery groups. The optimal timing of surgery should be individualized on a case-to-case basis.

Keywords: Infective endocarditis, Early surgery, Neurologic complication, Stroke, Cerebral infarction

\section{Background}

Cerebral infarction $(\mathrm{CI})$ is still one of the most common and fatal complications of infective endocarditis (IE). The incidence of CI varies from 10 to $40 \%$ [1, 2], with an increased risk of mortality [3, 4]. The timing of surgery for IE with neurologic complications remains controversial since early surgery might result in conversion into hemorrhagic stroke as a result of systemic anticoagulation during cardiopulmonary bypass, or the exacerbation of an ischemic stroke from hypotension

\footnotetext{
*Correspondence: taichiro@1997.jukuin.keio.ac.jp

${ }^{2}$ Department of General Thoracic Surgery, Yamanashi Central Hospital, Yamanashi 400-8506, Japan

Full list of author information is available at the end of the article
}

during surgery, although late surgery might result in continued neurological insult from embolic events. A previous meta-analysis showed that early surgery was associated with a significant increase in perioperative mortality and neurological deterioration in patients with IE complicated with neurologic events [5]. However, the outcomes beyond the perioperative period were not analyzed as many studies did not investigate long-term outcomes or just provided Kaplan-Meier curves without hazard ratios [HRs]. We previously reported a method to extract HRs from Kaplan-Meier curves [6]. By using this method and updating the available studies, we conducted a meta-analysis comparing mid- to long-term

(c) The Author(s). 2021 Open Access This article is licensed under a Creative Commons Attribution 4.0 International License, which permits use, sharing, adaptation, distribution and reproduction in any medium or format, as long as you give appropriate credit to the original author(s) and the source, provide a link to the Creative Commons licence, and indicate if changes were made. The images or other third party material in this article are included in the article's Creative Commons licence, unless indicated otherwise in a credit line to the material. If material is not included in the article's Creative Commons licence and your intended use is not permitted by statutory regulation or exceeds the permitted use, you will need to obtain permission directly from the copyright holder. To view a copy of this licence, visit http://creativecommons.org/licenses/by/4.0/ The Creative Commons Public Domain Dedication waiver (http://creativecommons.org/publicdomain/zero/1.0/) applies to the data made available in this article, unless otherwise stated in a credit line to the data. 
outcomes of early and late surgery in patients with IE complicated with neurologic events.

\section{Methods}

All studies that investigated early and late surgery in patients with IE and neurologic complications were identified using a two-level strategy. First, databases including MEDLINE and EMBASE were searched on July 27, 2020, using Web-based search engines (PubMed and OVID). Second, relevant studies were identified through a manual search of secondary sources, including references of initially identified articles, reviews, and commentaries. All references were downloaded for consolidation, elimination of duplicates, and further analyses. Search terms included "endocarditis," "early or timing," and "surgery or surgical." We did not apply language limitations. Two independent and blinded authors (Y.Y. and T.G.) reviewed the search results separately to select the studies based on present inclusion and exclusion criteria. Disagreements were resolved by means of a consensus-based discussion.
The included studies met the following criteria: the study was a randomized controlled trial or an observational study, the study population consisted of patients with IE and neurologic complications including CI or intracranial hemorrhage, the enrolled patients were assigned to the early surgery group and the late surgery group, and the outcomes included all-cause mortality with more than 6 months of follow-up. The definitions of early and late surgery were according to each study.

The primary endpoint was all-cause mortality, and the secondary endpoint was recurrence. The review was conducted according to the Preferred Reporting Items for Systematic Reviews and Meta-Analyses statement standards [7]. HRs for all-cause mortality and recurrence were extracted from each study. The adjusted HR was extracted if available. If the HR was not described in a study, then the HR was calculated from the KaplanMeier curve if available using the "HR-calculation spreadsheet" developed by Tierney et al. [8] based on standard statistical methods reported by Palmar et al. [9] and Williamson et al. [10]. If a Kaplan-Meier curve was not provided in a study, then the risk ratio was

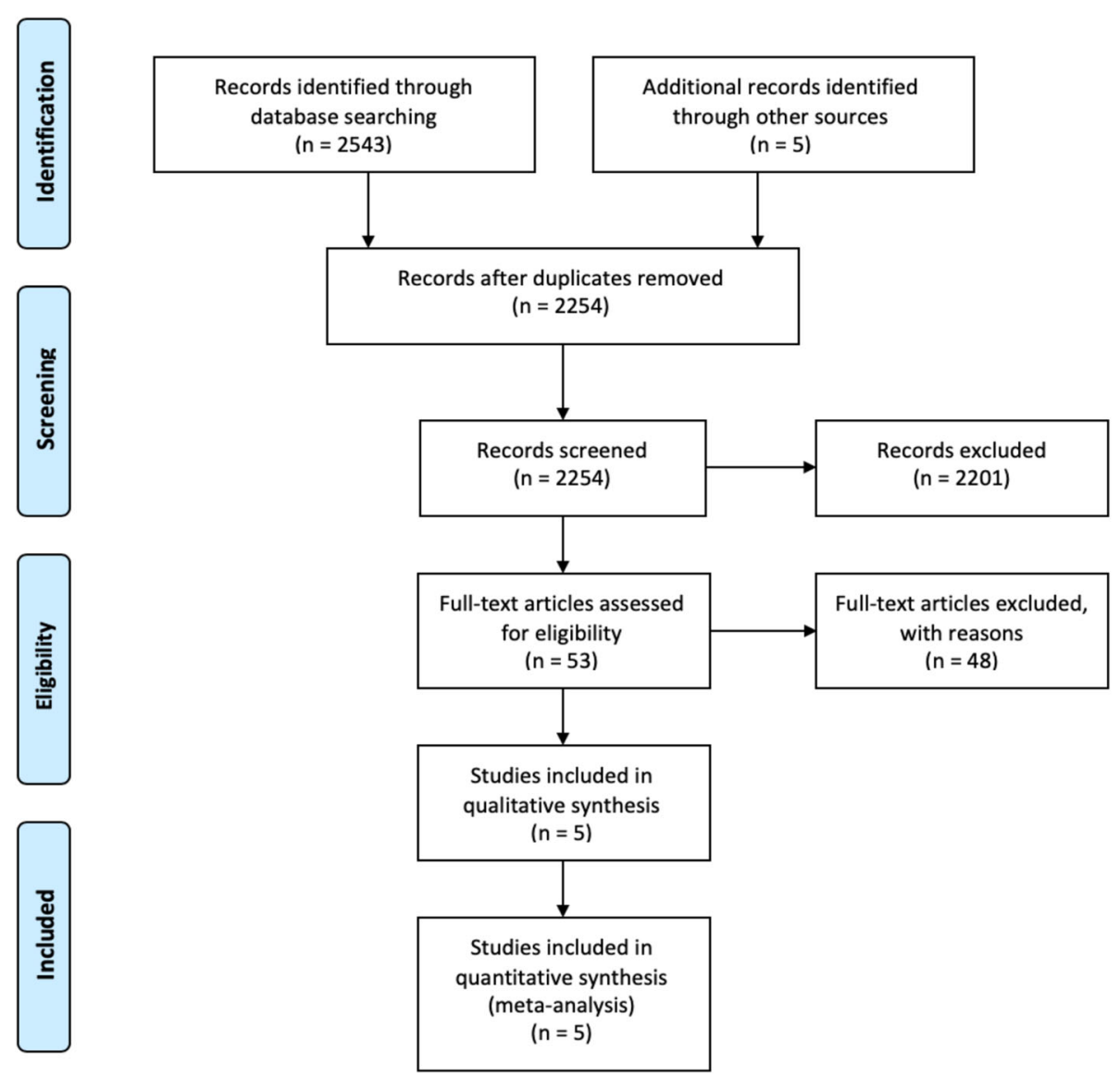

Fig. 1 Workflow for the selection of eligible original papers according to the PRISMA (Preferred Reporting Items for Systematic Reviews and Meta-Analyses) criteria for our original meta-analysis 
Table 1 Summary of included studies

\begin{tabular}{|c|c|c|c|c|c|c|c|c|}
\hline \multirow[t]{2}{*}{ Author } & \multirow[t]{2}{*}{ Year } & \multirow[t]{2}{*}{ Follow-up (months) } & \multirow{2}{*}{$\begin{array}{l}\text { Definition of early surgery } \\
\text { Early }\end{array}$} & \multicolumn{2}{|c|}{ Mean or median time to surgery (day) } & \multirow[t]{2}{*}{ Patients (n) } & \multirow[t]{2}{*}{ Early $(n)$} & \multirow[t]{2}{*}{ Late $(\mathrm{n}$} \\
\hline & & & & Early & Late & & & \\
\hline Thuny [13] & 2009 & 6 & $<7$ days & 3 & 19 & 241 & 95 & 146 \\
\hline Kim [14] & 2011 & 62 & $<14$ days & 3 & 20 & 56 & 34 & 22 \\
\hline Barsic [15] & 2012 & 12 & $<7$ days & NA & NA & 56 & 34 & 22 \\
\hline Oh [16] & 2016 & 51 & $<7$ days & 4 & 17 & 39 & 20 & 19 \\
\hline Samura [17] & 2019 & 60 & $<3$ days & 1 & 16 & 90 & 45 & 45 \\
\hline \multicolumn{2}{|c|}{ Age, median or mean \pm SD } & \multicolumn{2}{|l|}{ Female (\%) } & \multicolumn{2}{|c|}{ Diabetes (\%) } & \multicolumn{3}{|l|}{ CHF (\%) } \\
\hline Early & Late & Early & Late & Early & Late & Early & Late & \\
\hline $53 \pm 16$ & $58 \pm 15$ & 27 & 21 & 10 & 15 & 46 & 40 & \\
\hline $44 \pm 14$ & $40 \pm 16$ & 32 & 36 & 9 & 14 & NA & NA & \\
\hline 53 & 57 & 31 & 32 & 24 & 17 & NA & NA & \\
\hline $53 \pm 15$ & $45 \pm 15$ & 25 & 42 & 10 & 5 & 50 & 42 & \\
\hline 64 & 65 & 44 & 36 & 24 & 36 & NA & NA & \\
\hline \multicolumn{4}{|c|}{ Valve involved } & \multicolumn{2}{|c|}{ Prosthetic valve (\%) } & \multicolumn{3}{|c|}{ Cerebral hemorrhage (\%) } \\
\hline \multicolumn{2}{|l|}{ Early } & \multicolumn{2}{|l|}{ Late } & Early & Late & Early & \multicolumn{2}{|l|}{ Late } \\
\hline \multicolumn{2}{|c|}{ A-64\%, M-53\%, B-19\% } & \multicolumn{2}{|l|}{ M-70\%, B-50\%, T-22\% } & 21 & 31 & 2 & \multicolumn{2}{|l|}{5} \\
\hline \multicolumn{2}{|c|}{ A-35\%, M-53\%, B-12\% } & \multicolumn{2}{|l|}{ A-27\%, M-55\%, B-18\% } & 3 & 27 & 14 & \multicolumn{2}{|l|}{41} \\
\hline \multicolumn{2}{|c|}{ A-60\%, M-43\% } & \multicolumn{2}{|l|}{ A- $48 \%, M-58 \%$} & 22 & 23 & NA & \multicolumn{2}{|l|}{ NA } \\
\hline \multicolumn{2}{|c|}{ A-55\%, M-55\%, T-5\% } & \multicolumn{2}{|l|}{ A-47\%, M-79\% } & 45 & 37 & 20 & \multicolumn{2}{|l|}{32} \\
\hline \multicolumn{2}{|c|}{ A-45\%, M-71\% } & \multicolumn{2}{|l|}{ A-45\%, M-64\% } & 19 & 21 & 0 & \multicolumn{2}{|l|}{0} \\
\hline
\end{tabular}

A Aortic valve, $B$ Aortic and mitral valves, CHF Congestive heart failure, $M$ Mitral valve, NA Not available, $T$ Tricuspid valve

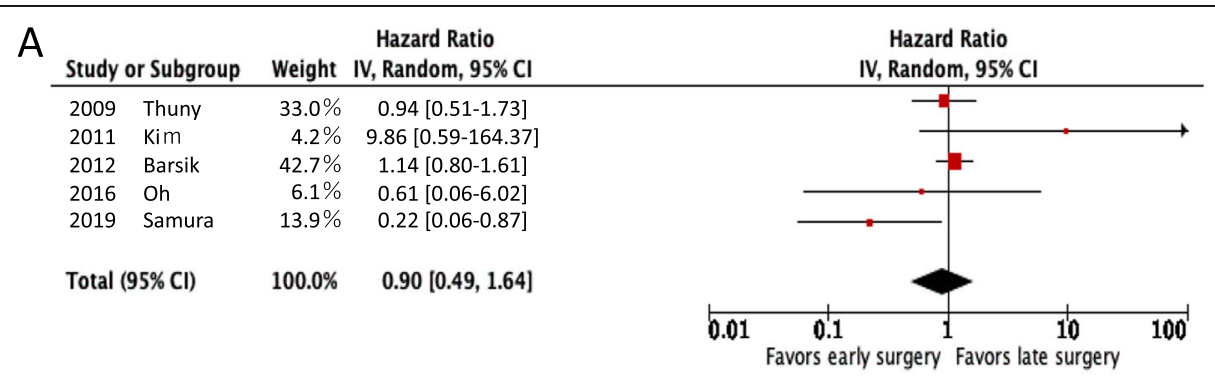

B

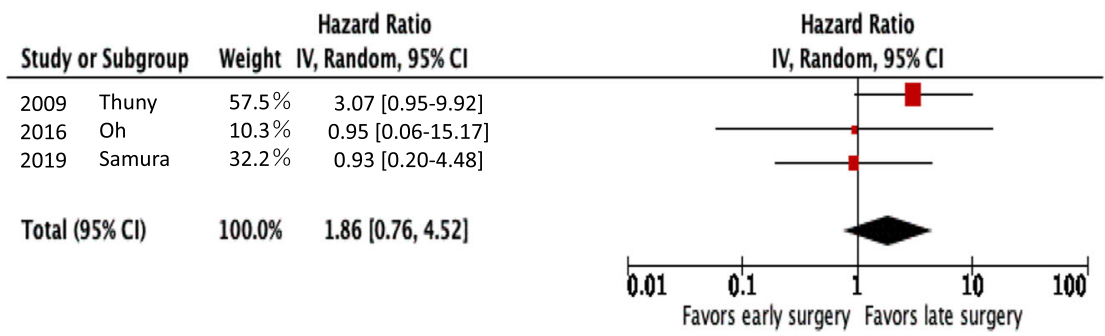

Fig. 2 Comparison of all-cause mortality (a) and recurrence (b) between the early surgery and late surgery groups using the random-effects model in the original studies from the reviewed meta-analysis. The left portion of the figure shows the studies analyzed with their corresponding hazard ratios and lower and upper limits. The right portion of the figure shows a forest plot of the data. The horizontal lines represent the values within the $95 \% \mathrm{Cl}$ of the underlying effects. The vertical line indicates a hazard ratio of 1 . Cl=confidence interval; $\mathrm{HR}=$ hazard ratio;

IV = inverse variance 
calculated from the event number and the patient number. Review Manager (RevMan) Version 5.3 (Nordic Cochrane Centre, the Cochrane Collaboration, 2012, Copenhagen, Denmark) was used to combine HRs in the random-effects model. The random-effects model was used in each outcome regardless of the heterogeneity among studies as it allowed for a more conservative assessment of the pooled effect size. ProMeta 3 software (https://idostatistics.com/prometa3/) was used to perform sensitivity analyses and examine funnel-plot asymmetry. Funnel-plot asymmetry suggesting publication bias was assessed mathematically using Egger's linear-regression test [11]. Significant heterogeneity was considered to be present when the $\mathrm{I}^{2}$ index was over $50 \%$ or the $\mathrm{P}$ for heterogeneity was <.05. Sensitivity analyses were performed by eliminating one study at a time to confirm that our findings were not derived from any single study [12].

\section{Results}

Our search identified five eligible studies [13-17], which were all observational studies consisting of a total of 624 patients with IE complicated with neurologic events assigned to the early surgery $(n=252)$ or late surgery groups $(n=372)$ (Fig. 1$)$. The study profile and patient characteristics are summarized in Table 1.

Pooled analyses demonstrated that all-cause mortality was similar between the early and late surgery groups (HR $[95 \%$ confidence interval $[\mathrm{CI}]]=0.90[0.49-1.64]$;

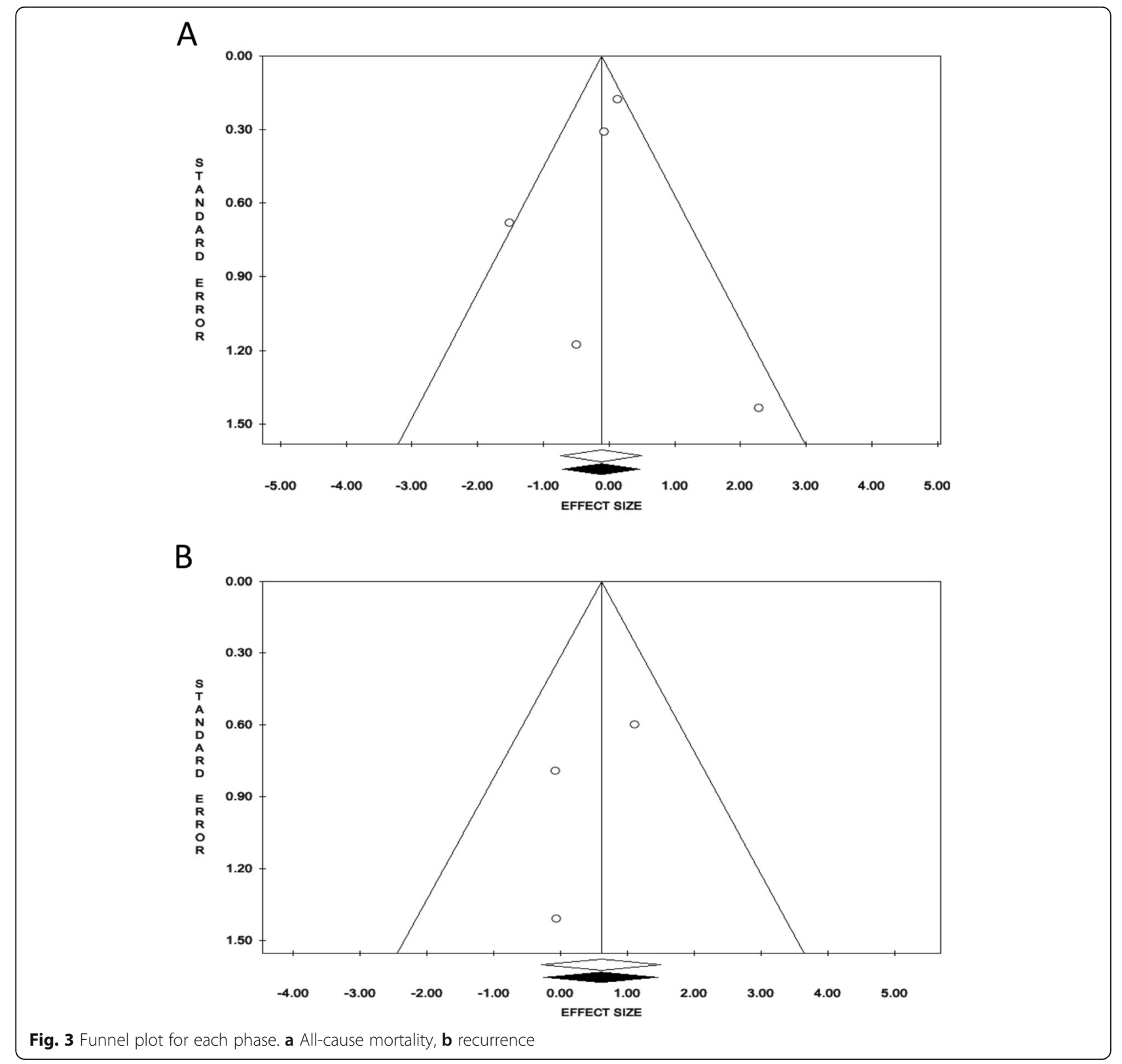


$P=0.10 ; \mathrm{I}^{2}=49 \%$ ) (Fig. 2a). Likewise, the recurrence rates were similar in both groups (HR [95\% CI] $=1.86$ [0.76-4.52]; $P=0.43 ; \mathrm{I}^{2}=0 \%$ ) (Fig. 2b).

Publication bias was assessed using funnel plots (Fig. 3), which showed no evidence of publication bias in the analyses of all-cause mortality and recurrence, respectively $(P=0.75,0.51)$. In terms of sensitivity analyses (Fig. 4), eliminating any single study did not change the primary results (pooling all the studies) of both all-cause mortality and recurrence.

\section{Discussion}

This meta-analysis demonstrated that early and late surgery in patients with IE complicated with CI were associated with similar rates of all-cause mortality and recurrence. IE remains a major illness with a high mortality secondary to complications including congestive heart failure and neurologic events $[18,19]$. Current guidelines recommend early surgery when specific parameters are met, such as recurrent emboli or large vegetation [20, 21]. A previous meta-analysis demonstrated that early surgery was associated with significant reduction in all-cause mortality in patients with IE [22]. However, early surgery might have an opposite effect after IE is complicated with neurologic events, since anticoagulation during cardiopulmonary bypass can turn an ischemic stroke into a hemorrhagic stroke, or exacerbate a stroke due to hypotension during operation. Current guidelines recommend delaying surgery for 3 to 4 weeks in IE patients with major or hemorrhagic stroke [23, 24]. Similarly, a recent meta-analysis showed that early surgery was associated with increased mortality and neurological exacerbation in patients with hemorrhagic stroke as well as ischemic stroke [5]. However, they were unable to analyze the outcomes beyond the perioperative period owing to scarcity of data on mid- to long-term outcomes.

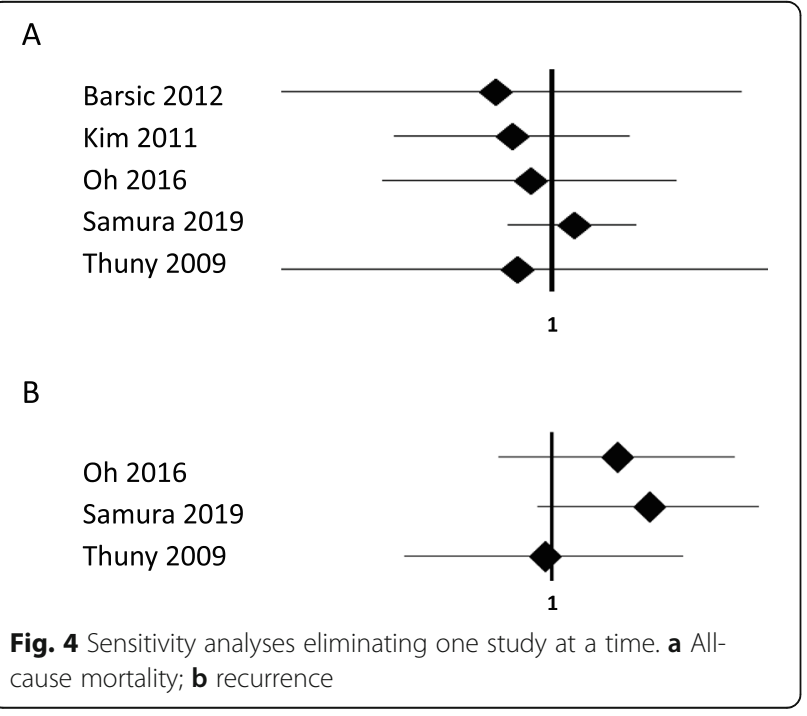

This is the first meta-analysis comparing the outcomes beyond the perioperative period between early and late surgery in patients with IE complicated with CI. Although previous meta-analyses demonstrated worse perioperative mortality with early surgery than that with late surgery $[5,22]$, our results showed similar mortality and recurrence rates. Furthermore, leave-one-out sensitivity analysis showed that eliminating any one of those studies did not change the outcomes, suggesting that our findings were not derived from any single study. This could be attributed to the fact that $40-60 \%$ of patients with IE develop heart failure because of structural damage $[25,26]$, and early surgery might prevent the development of heart failure caused by progressive regurgitation [27]. Therefore, although early surgery might increase preoperative mortality and neurologic complications in patients with IE complicated with neurologic events [5], it might have a positive effect on long-term outcomes by preserving cardiac function.

Our analysis has several limitations. First, our study comprised observational studies and is therefore subject to possible selection bias. Second, we did not analyze perioperative outcomes, since a previous meta-analysis including 27 observational studies [5] was conducted and the perioperative outcomes were thoroughly analyzed. Although they could not analyze the outcomes beyond the perioperative period, we were able to analyze them by extracting the HR from the Kaplan-Meier curve [6]. Third, the definition of early surgery varied among the studies, ranging from 3 to 14 days. Finally, there might be survivor bias in the late surgery group, and we could not assess how many patients died while waiting for the surgery.

\section{Conclusions}

Our meta-analysis showed similar mortality and recurrent rates between early and late surgery in patients with IE complicated with neurologic events. The optimal timing of surgery should be individualized on a case-to-case basis. Further trials with long-term outcomes are warranted.

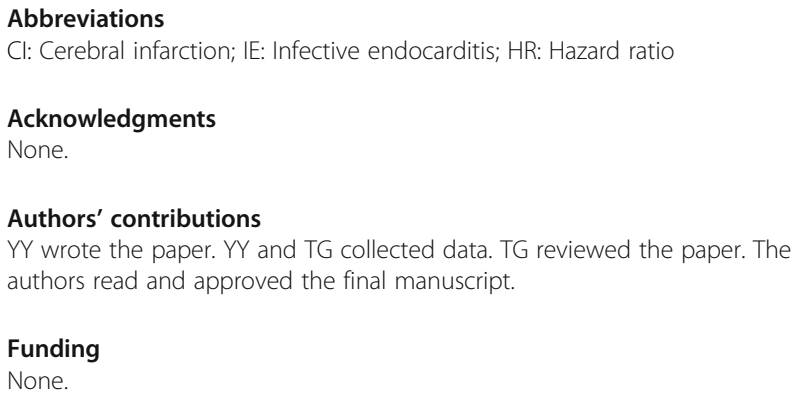




\section{Declarations}

\section{Ethics approval and consent to participate}

Not applicable.

\section{Consent for publication}

Not applicable.

\section{Competing interests}

None.

\section{Author details}

'Department of Surgery, St. Luke's University Health Network, Bethlehem, PA, USA. ${ }^{2}$ Department of General Thoracic Surgery, Yamanashi Central Hospital, Yamanashi 400-8506, Japan.

Received: 18 October 2020 Accepted: 11 March 2021

Published online: 25 March 2021

\section{References}

1. Snygg-Martin U, Gustafsson L, Rosengren L, Alsiö Å, Ackerholm P, Andersson R, Olaison L. Cerebrovascular complications in patients with leftsided infective endocarditis are common: a prospective study using magnetic resonance imaging and neurochemical brain damage markers. Clin Infect Dis. 2008:47(1):23-30. https://doi.org/10.1086/588663.

2. Thuny F, Di Salvo G, Belliard O, et al. Risk of embolism and death in infective endocarditis: prognostic value of echocardiography: a prospective multicenter study. Circulation. 2005;112(1):69-75. https://doi.org/10.1161/ CIRCULATIONAHA.104.493155.

3. Ruttmann E, Willeit J, Ulmer H, Chevtchik O, Höfer D, Poewe W, Laufer $\ddot{G}_{\text {, }}$ Müller LC. Neurological outcome of septic cardioembolic stroke after infective endocarditis. Stroke. 2006;37(8):2094-9. https://doi.org/10.1161/01. STR.0000229894.28591.3f

4. Anderson DJ, Goldstein LB, Wilkinson WE, Corey GR, Cabell CH, Sanders LL, Sexton DJ. Stroke location, characterization, severity, and outcome in mitral vs aortic valve endocarditis. Neurology. 2003;61(10):1341-6. https://doi.org/1 0.1212/01.WNL.0000094359.47929.E4.

5. Tam DY, Yanagawa B, Verma S, Ruel M, Fremes SE, Mazine A, Adams S, Friedrich JO. Early vs late surgery for patients with endocarditis and neurological injury: a systematic review and meta-analysis. Can J Cardiol. 2018;34(9):1185-99. https://doi.org/10.1016/j.cjca.2018.05.010.

6. Yokoyama $Y$, Kuno T, Takagi H. Meta-analysis of phase-specific survival after elective endovascular versus surgical repair of abdominal aortic aneurysm from randomized controlled trials and propensity score-matched studies [published online ahead of print, 2020 Apr 21]. J Vasc Surg. 2020;507415214(20):30595-4.

7. Liberati A, Altman DG, Tetzlaff J, Mulrow C, Gøtzsche PC, loannidis JP, Clarke M, Devereaux PJ, Kleijnen J, Moher D. The PRISMA statement for reporting systematic reviews and meta-analyses of studies that evaluate health care interventions: explanation and elaboration. Ann Intern Med. 2009;151(4): W65-94. https://doi.org/10.7326/0003-4819-151-4-200908180-00136.

8. Tierney JF, Stewart LA, Ghersi D, Burdett S, Sydes MR. Practical methods for incorporating summary time-to-event data into meta-analysis. Trials. 2007; 8(1):16. https://doi.org/10.1186/1745-6215-8-16.

9. Parmar MK, Torri V, Stewart L. Extracting summary statistics to perform metaanalyses of the published literature for survival endpoints. Stat Med. 1998;17(24):2815-34. https://doi.org/10.1002/(SICI)1097-0258(19981230)17:24 $<2815$ ::AID-SIM110>3.0.CO;2-8.

10. Williamson PR, Smith $C T$, Hutton JL, Marson AG. Aggregate data metaanalysis with time-to-event outcomes. Stat Med. 2002;21(22):3337-51. https://doi.org/10.1002/sim.1303.

11. Egger M, Davey Smith $G$, Schneider M, et al. Bias in meta-analysis detected by a simple, graphical test. BMJ. 1997;315(7109):629-6349310563. https://doi org/10.1136/bmj.315.7109.629.

12. Wang ZY, Zhao K, Zheng J, Rossmiller B, Ildefonso C, Biswal M, Zhao PQ. Systematic review and meta-analysis of the association between complement factor H $162 \mathrm{~V}$ polymorphism and risk of polypoidal choroidal vasculopathy in Asian populations. PLoS One. 2014;9(2):e88324. https://doi. org/10.1371/journal.pone.0088324.

13. Thuny F, Beurtheret S, Mancini J, Gariboldi V, Casalta JP, Riberi A, Giorgi R, Gouriet F, Tafanelli L, Avierinos JF, Renard S, Collart F, Raoult D, Habib G.
The timing of surgery influences mortality and morbidity in adults with severe complicated infective endocarditis: a propensity analysis. Eur Heart J. 2011;32(16):2027-33. https://doi.org/10.1093/eurheartj/ehp089.

14. Kim GS, Kim JB, Jung SH, Yun TJ, Choo SJ, Chung CH, Lee JW. Surgical Management of Infective Endocarditis Complicated by embolic stroke: early versus delayed surgery. Korean J Thorac Cardiovasc Surg. 2011;44(5):332-7. https://doi.org/10.5090/kjtcs.2011.44.5.332.

15. Barsic B, Dickerman S, Krajinovic V, Pappas P, Altclas J, Carosi G, Casabé JH, Chu VH, Delahaye F, Edathodu J, Fortes CQ, Olaison L, Pangercic A, Patel M, Rudez I, Tamin SS, Vincelj J, Bayer AS, Wang A, for the International Collaboration on Endocarditis-Prospective Cohort Study (ICE-PCS) Investigators. International collaboration on endocarditis-prospective cohort study investigators. Influence of the timing of cardiac surgery on the outcome of patients with infective endocarditis and stroke. Clin Infect Dis. 2013;56(2):209-17. https://doi.org/10.1093/cid/cis878.

16. Oh TH, Wang TK, Pemberton JA, et al. Early or late surgery for endocarditis with neurological complications. Asian Cardiovasc Thorac Ann. 2016;24(5): 435-40. https://doi.org/10.1177/0218492316646903.

17. Samura T, Yoshioka D, Toda K, Sakaniwa R, Yokoyama J, Suzuki K, Miyagawa S, Yoshikawa Y, Hata H, Takano H, Matsumiya G, Monta O, Sakaguchi T, Fukuda H, Oscar Study Group, Sawa Y. Emergency valve surgery improves clinical results in patients with infective endocarditis complicated with acute cerebral infarction: analysis using propensity score matchingt. Eur J Cardiothorac Surg. 2019:56(5):942-9. https://doi.org/10.1093/ejcts/ezz100.

18. Thuny F, Grisoli D, Collart F, Habib G, Raoult D. Management of infective endocarditis: challenges and perspectives. Lancet. 2012;379(9819):965-75. https://doi.org/10.1016/S0140-6736(11)60755-1.

19. Bashore TM, Cabell C, Fowler V Jr. Update on infective endocarditis. Curr Probl Cardiol. 2006;31(4):274-352. https://doi.org/10.1016/j.cpcardiol.2005.12.001.

20. Winston LG, Bolger AF. Modern epidemiology, prophylaxis, and diagnosis and therapy for infective endocarditis. Curr Cardiol Rep. 2006;8(2):102-8. https://doi.org/10.1007/s11886-006-0020-3.

21. Tornos P, lung B, Permanyer-Miralda G, Baron G, Delahaye F, Gohlke-Bärwolf Ch, Butchart EG, Ravaud P, Vahanian A. Infective endocarditis in Europe: lessons from the euro heart survey. Heart. 2005;91(5):571-5. https://doi.org/1 $0.1136 /$ hrt.2003.032128.

22. Jia L, Wang Z, Fu Q, et al. Could early surgery get beneficial in adult patients with active native infective endocarditis? A Meta-Analysis. Biomed Res Int. 2017;2017:3459468.

23. Baddour LM, Wilson WR, Bayer AS, Fowler VG Jr, Tleyjeh IM, Rybak MJ, Barsic B, Lockhart PB, Gewitz MH, Levison ME, Bolger AF, Steckelberg JM, Baltimore RS, Fink AM, O'Gara P, Taubert KA, on behalf of the American Heart Association Committee on Rheumatic Fever, Endocarditis, and Kawasaki Disease of the Council on Cardiovascular Disease in the Young, Council on Clinical Cardiology, Council on Cardiovascular Surgery and Anesthesia, and Stroke Council. Infective endocarditis in adults: diagnosis, antimicrobial therapy, and management of complications: a scientific statement for healthcare professionals from the American Heart Association. Circulation. 2015;132(15):1435-86. https://doi.org/10.1161/CIR.0000000000000296.

24. Fukuda W, Daitoku K, Minakawa M, Fukui K, Suzuki Y, Fukuda I. Infective endocarditis with cerebrovascular complications: timing of surgical intervention. Interact Cardiovasc Thorac Surg. 2012;14(1):26-30. https://doi. org/10.1093/icvts/ivr038.

25. Nadji G, Rusinaru D, Rémadi JP, Jeu A, Sorel C, Tribouilloy C. Heart failure in left-sided native valve infective endocarditis: characteristics, prognosis, and results of surgical treatment. Eur J Heart Fail. 2009;11(7):668-75. https://doi. org/10.1093/eurjhf/hfp077.

26. Revilla A, López J, Vilacosta I, Villacorta E, Rollán MJ, Echevarría JR, Carrascal Y, d Stefano S, Fulquet E, Rodríguez E, Fiz L, San Román JA. Clinical and prognostic profile of patients with infective endocarditis who need urgent surgery. Eur Heart J. 2007;28(1):65-71. https://doi.org/10.1093/eurhearti/ehl315.

27. Funakoshi S, Kaji S, Yamamuro A, Tani T, Kinoshita M, Okada Y, Furukawa Y. Impact of early surgery in the active phase on long-term outcomes in leftsided native valve infective endocarditis. J Thorac Cardiovasc Surg. 2011; 142(4):836-42. https://doi.org/10.1016/j.jtcvs.2011.01.040.

\section{Publisher's Note}

Springer Nature remains neutral with regard to jurisdictional claims in published maps and institutional affiliations. 